\title{
Short-term thinking behind dismal UK research spending
}

\section{London}

YET another report has been issued pointing out British industry's dismal performance in funding for research and development, this time by the Technology Requirements Board of the Department of Trade and Industry (DTI). But underlying the expected recommendations on increased support for "innovation" is the need for a fundamental change in the attitude of financial backers, away from a short-term profit-oriented outlook.

Industry-financed expenditure for research and development in the United Kingdom has grown at a lower rate than in other industrialized nations in the past 15 years (see figure), a fact reflected in a decline in patenting activity: the UK share of patents taken out in the United States has fallen by one-sixth since the mid1970s. Figures from the Organization for Economic Cooperation and Development

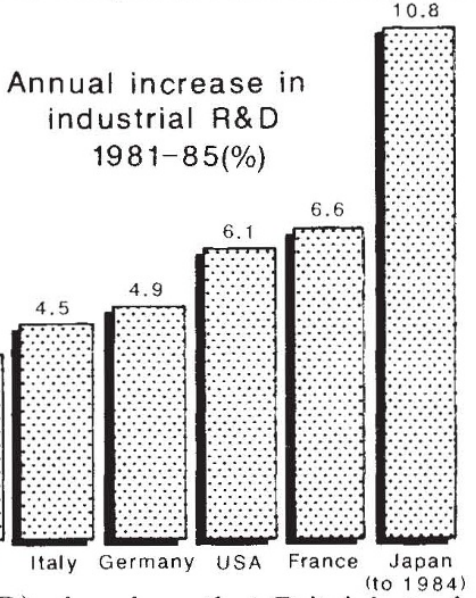

(OECD) also show that Britain's trade balance in high-technology products has deteriorated sharply.

The root of the problem lies to a large extent in the City, Britain's equivalent of Wall Street, where an attitude of 'short termism' prevails. Company shareholders, largely insurance companies, unit trusts and pension funds, expect higher short-term profits than in other countries. Investment in research and development can soak up immediate profits, resulting in a loss of interest income. Britain's high interest rates (11.6 per cent, compared to 7.5 in the United States, 6.5 in Japan and 5.4 in West Germany, according to OECD figures for 1985) mean that it is difficult for investment in research and development to compete. With the emphasis on profits rather than the expansion that would result from innovation, debate centres around short-term versus long-term benefits, and value for money in research and development.

Scientists and industrialists argue that shareholders must put a premium on growth and take pride in a company's expansion. They say that whatever the short-term profit level, a company that does not innovate must eventually die. "The short-term views of the City can't be used as an excuse for poor management", says Dr Penny Birdseye, deputy director of the Confederation of British Industry. "There is evidence that if the advantages of innovating are communicated well to shareholders, the support will come."

This week's report calls on industry to take advantage of Britain's high gross domestic product (GDP) growth rate by investing in long-term prospects for creating wealth. It recommends that industry should increase its support for research and development by 5 to 10 per cent a year, instead of the current 3.9 per cent.

Disclosure of research and development expenditure in company accounts is also recommended as a way to convey future prospects to investors. The government has supported this concept in a recent white paper, threatening to legislate if voluntary compliance is not forthcoming.

The technology board argues for a sharp increase in DTI support for innovation in industry, currently $£ 387$ million a year. It suggests that expenditure should focus on technology for information, advanced manufacturing, materials and biotechnology, and recommends encouragement of collaborative international projects such as the European Eureka programme and the LINK initiative for cooperation between industry and the universities.

Increased government support, not surprisingly, is another recommendation, especially for civil industrial development. In 1985, government support in this area, as a proportion of GDP, was $50-100$ per cent higher in Germany, Italy and France than in the United Kingdom. British government funding for civil industrial development was 0.088 per cent of GDP in 1985 , compared to 0.68 per cent for defence research and development.

One-quarter of military procurement spending goes for research and development, but the government is concerned that this may be too much. In its recent white paper, it announced the intention to reduce defence research and development spending because it may be taking scientific, engineering and skilled manpower resources from the civil sector. But this conclusion is not unanimously supported - some industrialists say such a move would harm Britain's balance of payments and threaten empolyment.

While industry pushes for more government palliatives to improve spending on

\section{Bids requested for centres of exellence}

\section{London}

THE first step has been taken towards a major reformation of research in British universities, with a letter sent out by the Science and Engineering Research Council (SERC) to all vice-chancellors and principals, inviting bids to set up interdisciplinary research centres.

The council intends to establish two or three centres annually over the next few years, to provide a focus for research in areas that cut across the normal university department structure and that are considered of strategic importance, including surface science, semiconductors and novel materials, molecular sciences, lasers in manufacturing, high-temperature superconductivity, engineering design, and process simulation, integration and control.

The new centres will be research groups in their own right, carrying out their own programmes of basic, strategic and applied research, advised by a management committee that will include academics and industrialists. Industry may also be involved in financing the centres.

SERC says it has no prejudgements about which higher education institutions will host the new research centres. Even the decisions about which topics will be focused on are not necessarily set in concrete. "A learning process is involved", says SERC chairman, Professor E.W.J. Mitchell. Financial support is also an uncertainty, and Mitchell acknowledges that the programme may face a short-term financial crisis.

Each inter-university centre will be based at one campus, possibly serving a group of universities and polytechnics in one locality. Each is expected to have a staff of about 40, comprising 15 technicians and 25 research and support staff.

Bids from interested institutions are due by the end of September, and SERC hopes to reach some decisions early in 1988 . Highest priority is being given to a centre on high-temperature superconductivity, and an announcement on its location is expected before the end of the year (see Nature, 328, 370; 1987). Kathy Johnston

innovation, the government is calling for industry to stand on its own feet. Industry points out that it is difficult to make changes overnight, and asks the government to help by bringing interest rates down and by encouraging a good scientific base, thereby increasing the number of scientists available to work in research and in finance houses. Industrialists have set up a task force with representatives from the City, with a report expected later this year. There are signs that all the discussion and debate is beginning to bring a change.
Kathy Johnston 